\title{
Fixed point theorem for generalized weak contractions satisfying rational expressions in ordered metric spaces
}

Nguyen Van Luong ${ }^{*}$ and Nguyen Xuan Thuan

* Correspondence: luonghdu@gmail.com

Department of Natural Sciences, Hong Duc University, Thanh Hoa, Vietnam

\begin{abstract}
In this paper, we prove a fixed point theorem for generalized weak contractions satisfying rational expressions in partially ordered metric spaces. The result is a generalization of a recent result of Harjani et al. (Abstr. Appl. Anal, Vol.2010, 1-8, 2010). An example is also given to show that our result is a proper generalization of the existing one.

2000 Mathematics Subject Classification: 47H10, 54H25.

Keywords: fixed point, generalized weak contraction, rational type, ordered metric spaces
\end{abstract}

\section{Introduction and preliminaries}

It is well known that the Banach contraction mapping principle is one of the pivotal results of analysis. Generalizations of this principle have been obtained in several directions. The following is an example of such generalizations. Jaggi in [1] proved the following theorem satisfying a contractive condition of rational type

Theorem 1.1. ([1]) Let $T$ be a continuous self-map defined on a complete metric space $(X, d)$. Suppose that $T$ satisfies the following condition:

$$
d(T x, T y) \leq \alpha \frac{d(x, T x) \cdot d(y, T y)}{d(x, y)}+\beta d(x, y)
$$

for all $x, y \in X, x \neq y$ and for some $\alpha, \beta \geq 0$ with $\alpha+\beta<1$, then $T$ has a unique fixed point in $X$.

Another generalization of the contraction principle was suggested by Alber and Guerre-Delabriere [2] in Hilbert spaces. Rhoades [3] has shown that their result is still valid in complete metric spaces.

Definition 1.2. ([3]) Let $(X, d)$ be a metric space. A mapping $T: X \rightarrow X$ is said to be $\phi$-weak contraction if

$$
d(T x, T y) \leq d(x, y)-\varphi(d(x, y))
$$

for all $x, y \in X$, where $\phi:[0, \infty) \rightarrow[0, \infty)$ is a continuous and non-decreasing function with $\phi(t)=0$ if and only if $t=0$.

(c) 2011 Luong and Thuan; licensee Springer. This is an Open Access article distributed under the terms of the Creative Commons Attribution License (http://creativecommons.org/licenses/by/2.0), which permits unrestricted use, distribution, and reproduction in any medium, provided the original work is properly cited. 
Theorem 1.3. ([3]) Let $(X, d)$ be a complete metric space and $T$ be a $\phi$-weak contraction on $X$. Then, $T$ has a unique fixed point.

In fact, while Alber and Guerre-Delabriere assumed an additional assumption $\lim _{t \rightarrow \infty}$ $\phi(t)=\infty$ on $\phi$, but Rhoades proved Theorem 1.3 without this particular condition. A number of extensions of Theorem 1.3 were presented in [4-9] and references therein. Some of these results were presented without the continuity and monotonicity of $\phi$.

Recently, existence of fixed points in partially ordered sets has been considered, and first results were obtain by Ran and Reurings [10] and then by Nieto and Lopez [11]. The following fixed point theorem is the version of theorems, which were proved in those papers.

Theorem 1.4. ([10,11]) Let $(X, \leq)$ be a partially ordered set, and suppose that there is a metric $d$ such that $(X, d)$ be a complete metric space. Let $T: X \rightarrow X$ be a nondecreasing mapping satisfying the following inequality

$$
d(T x, T y) \leq k d(x, y), \quad \text { for all } \quad x, y \in X \text { with } x \leq y,
$$

where $k \in(0,1)$. Also, assume either

(i) $T$ is continuous or

(ii) $X$ has the property:

$$
\text { If a non - decreasing sequence }\left\{x_{n}\right\} \text { in } X \text { converges to } x \in X \text { then } x_{n} \leq x \text { for all } n
$$

If there exists $x_{0} \in X$ such that $x_{0} \leq T x_{0}$, then $T$ has a fixed point.

Besides, applications to matrix equations and ordinary differential equations were presented in $[10,11]$. Afterward, coupled fixed point and common fixed point theorems and their applications to periodic boundary value problems and integral equations were given in [5-7,12-19]. In particular, Harjani and Sadarangani [5] proved some fixed point theorems in the context of ordered metric spaces as the extensions of Theorem 1.3. We state one of their results.

Theorem 1.5. ([5]) Let $(X, \leq)$ be a partially ordered set and suppose that there is a metric $d$ such that $(X, d)$ be a complete metric space. Let $T: X \rightarrow X$ be a non-decreasing mapping satisfying the following inequality

$$
d(T x, T y) \leq d(x, y)-\varphi(d(x, y)), \quad \text { for all } x, y \in X \text { with } x \leq y,
$$

where $\phi:[0, \infty) \rightarrow[0, \infty)$ is a continuous and non-decreasing function with $\phi(t)=0$ if and only if $t=0$. Also, assume either

(i) $T$ is continuous or

(ii) $X$ has the property (1).

If there exists $x_{0} \in X$ such that $x_{0} \leq T x_{0}$, then $T$ has a fixed point.

In addition, Harjani et al. in [12] proved the following theorem as a version of Theorem 1.1 in partially ordered metric spaces where they replaced the condition (1) by a stronger condition, that is

If $\left\{x_{n}\right\}$ is a non - decreasing sequence in $X$ such that $x_{n} \rightarrow x$ then $x=\sup \left\{x_{n}\right\}$. 
Theorem 1.6. ([12]) Let $(X, \leq)$ be a partially ordered set and suppose that there is a metric $d$ such that $(X, d)$ be a complete metric space. Let $T: X \rightarrow X$ be a nondecreasing mapping such that

$$
d(T x, T y) \leq \alpha \frac{d(x, T x) \cdot d(y, T y)}{d(x, y)}+\beta d(x, y), \text { for all } x, y \in X \text { with } x \geq y, x \neq y,
$$

where $0 \leq \alpha, \beta$ and $\alpha+\beta<1$. Also, assume either

(i) $T$ is continuous or

(ii) $X$ has the property (2).

If there exists $x_{0} \in X$ such that $x_{0} \leq T x_{0}$, then $T$ has a fixed point.

In this paper, we prove a fixed point theorem for generalized weak contractions satisfying rational expressions in partially metric spaces, which is a generalization of the result of Harjani et al. [12]. We also give an example to show that our result is a proper extension of the result in [12].

\section{Main theorem}

Theorem 2.1. Let $(X, \leq)$ be a partially ordered set, and suppose that there is a metric $d$ such that $(X, d)$ be a complete metric space. Let $T: X \rightarrow X$ be a non-decreasing mapping satisfying the following inequality

$$
d(T x, T y) \leq M(x, y)-\varphi(M(x, y)), \text { for all } x, y \in X \text { with } x \geq y, x \neq y,
$$

where $\phi:[0, \infty) \rightarrow[0, \infty)$ is a lower semi-continuous function with $\phi(t)=0$ if and only if $t=0$, and

$$
M(x, y)=\max \left\{\frac{d(x, T x) \cdot d(y, T y)}{d(x, y)}, d(x, y)\right\} .
$$

Also, assume either

(i) $T$ is continuous or

(ii) $X$ has the property (2).

If there exists $x_{0} \in X$ such that $x_{0} \leq T x_{0}$, then $T$ has a fixed point.

Proof. Let $x_{0} \in X$ be such that $x_{0} \leq T x_{0}$, we construct the sequence $\left\{x_{n}\right\}$ in $X$ as follows

$$
x_{n+1}=T x_{n}, \quad n=0,1,2, \ldots
$$

Since $T$ is a non-decreasing mapping, by induction, we can show that

$$
x_{0} \leq x_{1} \leq x_{2} \leq \cdots \leq x_{n} \leq x_{n+1} \leq \cdots
$$

If there exists $n_{0}$ such that $x_{n_{0}}=x_{n_{0}+1}$, then $x_{n_{0}}=x_{n_{0}+1}=T x_{n_{0}}$. This means that $x_{n_{0}}$ is a fixed point of $T$ and the proof is finished. Thus, we can suppose that $x_{n} \neq x_{n+1}$ for all $n$. 
Since $x_{n}>x_{n-1}$ for all $n \geq 1$, from (4), we have

$$
\begin{aligned}
d\left(x_{n+1}, x_{n}\right)= & d\left(T x_{n}, T x_{n-1}\right) \\
\leq & \max \left\{\frac{d\left(x_{n}, T x_{n}\right) \cdot d\left(x_{n-1}, T x_{n-1}\right)}{d\left(x_{n}, x_{n-1}\right)}, d\left(x_{n}, x_{n-1}\right)\right\} \\
& -\varphi\left(\max \left\{\frac{d\left(x_{n}, T x_{n}\right) \cdot d\left(x_{n-1}, T x_{n-1}\right)}{d\left(x_{n}, x_{n-1}\right)}, d\left(x_{n}, x_{n-1}\right)\right\}\right) \\
= & \max \left\{d\left(x_{n+1}, x_{n}\right), d\left(x_{n}, x_{n-1}\right)\right\} \\
& -\varphi\left(\max \left\{d\left(x_{n+1}, x_{n}\right), d\left(x_{n}, x_{n-1}\right)\right\}\right)
\end{aligned}
$$

Suppose that there exists $m_{0}$ such that $d\left(x_{m_{0}+1}, x_{m_{0}}\right)>d\left(x_{m_{0}}, x_{m_{0}-1}\right)$, from (7), we have

$$
\begin{aligned}
d\left(x_{m_{0}+1}, x_{m_{0}}\right) \leq & \max \left\{d\left(x_{m_{0}+1}, x_{m_{0}}\right), d\left(x_{m_{0}}, x_{m_{0}-1}\right)\right\} \\
& -\varphi\left(\max \left\{d\left(x_{m_{0}+1}, x_{m_{0}}\right), d\left(x_{m_{0}}, x_{m_{0}-1}\right)\right\}\right) \\
= & d\left(x_{m_{0}+1}, x_{m_{0}}\right)-\varphi\left(d\left(x_{m_{0}+1}, x_{m_{0}}\right)\right)<d\left(x_{m_{0}+1}, x_{m_{0}}\right)
\end{aligned}
$$

which is a contradiction. Hence, $d\left(x_{n+1}, x_{n}\right) \leq d\left(x_{n}, x_{n-1}\right)$ for all $n \geq 1$.

Since $\left\{d\left(x_{n+1}, x_{n}\right)\right\}$ is a non-increasing sequence of positive real numbers, there exists $\delta \geq 0$ such that

$$
\lim _{n \rightarrow \infty} d\left(x_{n+1}, x_{n}\right)=\delta
$$

We shall show that $\delta=0$. Assume, to the contray, that $\delta>0$. Taking the upper limit as $n \rightarrow \infty$ in (7) and using the properties of the function $\phi$, we get

$$
\delta \leq \delta-\lim _{n \rightarrow \infty} \inf \varphi\left(\max \left\{d\left(x_{n+1}, x_{n}\right), d\left(x_{n}, x_{n-1}\right)\right\}\right) \leq \delta-\varphi(\delta)<\delta
$$

which is a contradiction. Therefore, $\delta=0$, that is,

$$
\lim _{n \rightarrow \infty} d\left(x_{n+1}, x_{n}\right)=0
$$

In what follows, we shall prove that $\left\{x_{n}\right\}$ is a Cauchy sequence. Suppose, to the contrary, that $\left\{x_{n}\right\}$ is not a Cauchy sequence. Then, there exists $\varepsilon>0$ such that we can find subsequences $\left\{x_{m(k)}\right\},\left\{x_{n(k)}\right\}$ of $\left\{x_{n}\right\}$ with $n(k)>m(k) \geq k$ satisfying

$$
d\left(x_{m(k)}, x_{n(k)}\right) \geq \varepsilon
$$

Further, corresponding to $m(k)$, we can choose $n(k)$ in such way that it is the smallest integer with $n(k)>m(k) \geq k$ satisfying (9). Hence,

$$
d\left(x_{m(k)}, x_{n(k)-1}\right)<\varepsilon
$$

We have

$$
\varepsilon \leq d\left(x_{m(k)}, x_{n(k)}\right) \leq d\left(x_{m(k)}, x_{n(k)-1}\right)+d\left(x_{n(k)-1}, x_{n(k)}\right)<\varepsilon+d\left(x_{n(k)-1}, x_{n(k)}\right)
$$

Taking $k \rightarrow \infty$ and using (8), we get

$$
\lim _{k \rightarrow \infty} d\left(x_{m(k)}, x_{n(k)}\right)=\varepsilon
$$

By the triangle inequality,

$$
\begin{aligned}
& d\left(x_{m(k)}, x_{n(k)}\right) \leq d\left(x_{m(k)}, x_{m(k)-1}\right)+d\left(x_{m(k)-1}, x_{n(k)-1}\right)+d\left(x_{n(k)-1}, x_{n(k)}\right), \\
& d\left(x_{m(k)-1}, x_{n(k)-1}\right) \leq d\left(x_{m(k)-1}, x_{m(k)}\right)+d\left(x_{m(k)}, x_{n(k)}\right)+d\left(x_{n(k)}, x_{n(k)-1}\right)
\end{aligned}
$$


Taking $k \rightarrow \infty$ in the above inequalities and using (7), (11), we obtain

$$
\lim _{k \rightarrow \infty} d\left(x_{m(k)-1}, x_{n(k)-1}\right)=\varepsilon
$$

Since $m(k)<n(k), x_{n(k)-1}>x_{m(k)-1}$, from (4), we have

$$
\begin{aligned}
& d\left(x_{n(k)}, x_{m(k)}\right)=d\left(T x_{n(k)-1}, T x_{m(k)-1}\right) \\
& \leq \max \left\{\frac{d\left(x_{n(k)-1}, T x_{n(k)-1}\right) d\left(x_{m(k)-1}, T x_{m(k)-1}\right)}{d\left(x_{n(k)-1}, x_{m(k)-1}\right)}, d\left(x_{n(k)-1}, x_{m(k)-1}\right)\right\} \\
& -\varphi\left(\max \left\{\frac{d\left(x_{n(k)-1}, T x_{n(k)-1}\right) \cdot d\left(x_{m(k)-1}, T x_{m(k)-1}\right)}{d\left(x_{n(k)-1}, x_{m(k)-1}\right)}, d\left(x_{n(k)-1}, x_{m(k)-1}\right)\right\}\right) \\
& \leq \max \left\{\frac{d\left(x_{n(k)-1}, x_{n(k)}\right) \cdot d\left(x_{m(k)-1}, x_{m(k)}\right)}{d\left(x_{n(k)-1}, x_{m(k)-1}\right)}, d\left(x_{n(k)-1}, x_{m(k)-1}\right)\right\} \\
& \quad-\varphi\left(\max \left\{\frac{d\left(x_{n(k)-1}, x_{n(k)}\right) \cdot d\left(x_{m(k)-1}, x_{m(k)}\right)}{d\left(x_{n(k)-1}, x_{m(k)-1}\right)}, d\left(x_{n(k)-1}, x_{m(k)-1}\right)\right\}\right)
\end{aligned}
$$

Taking upper limit as $k \rightarrow \infty$ in (13) and using (7), (11), (12) and the properties of the function $\phi$, we have

$$
\varepsilon \leq \max \{0, \varepsilon\}-\varphi(\max \{0, \varepsilon\})=\varepsilon-\varphi(\varepsilon)<\varepsilon
$$

which is a contradiction. Therefore, $\left\{x_{n}\right\}$ is a Cauchy sequence. Since $X$ is a complete metric space, there exists $x \in X$ such that $\lim _{n \rightarrow \infty} x_{n}=x$.

Now, suppose that the assumption (a) holds. The continuity of $T$ implies

$$
x=\lim _{n \rightarrow \infty} x_{n}=\lim _{n \rightarrow \infty} T x_{n-1}=T\left(\lim _{n \rightarrow \infty} x_{n-1}\right)=T x
$$

and this proved that $x$ is a fixed point of $T$.

Finally, suppose that the assumption (b) holds. Since $\left\{x_{n}\right\}$ is a non-decreasing sequence and $x_{n} \rightarrow x$, then $x=\sup \left\{x_{n}\right\}$. Particularly, $x_{n} \leq x$ for all $n$. Since $T$ is nondecreasing, $T x_{n} \leq T x$ for all $n$, that is, $x_{n+1} \leq T x$ for all $n$. Moreover, as $x_{n} \leq x_{n+1} \leq T x$ for all $n$ and $x=\sup \left\{x_{n}\right\}$, we obtain $x \leq T x$. Consider the sequence $\left\{y_{n}\right\}$ that is constructed as follows

$$
y_{0}=x, y_{n+1}=T y_{n}, n=0,1,2, \ldots
$$

Since $y_{0} \leq T y_{0}$, arguing like above part, we obtain that $\left\{y_{n}\right\}$ is a non-decreasing sequence and $\lim _{n \rightarrow \infty} y_{n}=\gamma$ for certain $y \in X$. By the assumption (b), we have $y=\sup \left\{y_{n}\right\}$.

Since $x_{n}<x=y_{0} \leq T x=T y_{0} \leq y_{n} \leq y$ for all $n$, suppose that $x \neq y$, from (4), we have

$$
\begin{aligned}
d\left(y_{n+1}, x_{n+1}\right)= & d\left(T x_{n}, T y_{n}\right) \\
\leq & \max \left\{\frac{d\left(y_{n}, T y_{n}\right) \cdot d\left(x_{n}, T x_{n}\right)}{d\left(y_{n}, x_{n}\right)}, d\left(y_{n}, x_{n}\right)\right\} \\
& -\varphi\left(\max \left\{\frac{d\left(y_{n}, T y_{n}\right) \cdot d\left(x_{n}, T x_{n}\right)}{d\left(y_{n}, x_{n}\right)}, d\left(y_{n}, x_{n}\right)\right\}\right) \\
= & \max \left\{\frac{d\left(y_{n}, y_{n+1}\right) \cdot d\left(x_{n}, x_{n+1}\right)}{d\left(y_{n}, x_{n}\right)}, d\left(y_{n}, x_{n}\right)\right\} \\
& -\varphi\left(\max \left\{\frac{d\left(y_{n}, y_{n+1}\right) \cdot d\left(x_{n}, x_{n+1}\right)}{d\left(y_{n}, x_{n}\right)}, d\left(y_{n}, x_{n}\right)\right\}\right)
\end{aligned}
$$


Taking upper limit as $n \rightarrow \infty$ in the above inequality, we have

$$
d(y, x) \leq \max \{0, d(y, x)\}-\varphi(\max \{0, d(y, x)\})<d(y, x)
$$

which is a contradiction. Hence, $x=y$. We have $x \leq T x \leq x$, therefore $T x=x$. That is, $x$ is a fixed point of $T$.

The proof is complete.

Corollary 2.2. Let $(X, \leq)$ be a partially ordered set, and suppose that there is a metric $d$ such that $(X, d)$ be a complete metric space. Let $T: X \rightarrow X$ be a non-decreasing mapping such that

$$
d(T x, T y) \leq k \max \left\{\frac{d(x, T x) \cdot d(y, T y)}{d(x, y)}, d(x, y)\right\},
$$

for all $x, y \in X$ with $x \geq y, x \neq y$, where $k \in(0,1)$. Also, assume either

(i) $T$ is continuous or

(ii) $X$ has the property (2).

If there exists $x_{0} \in X$ such that $x_{0} \leq T x_{0}$, then $T$ has a fixed point.

Proof. In Theorem 2.1, taking $\phi(t)=(1-k) t$, for all $t \in[0, \infty)$, we get Corollary 2.2.

$$
\square
$$

Remark 2.3. For $\alpha, \beta>0, \alpha+\beta<1$ and for all $x, y \in X, x \neq y$, we have

$$
\begin{aligned}
d(T x, T y) & \leq \alpha \frac{d(x, T x) \cdot d(y, T y)}{d(x, y)}+\beta d(x, y) \\
& \leq(\alpha+\beta) \max \left\{\frac{d(x, T x) \cdot d(y, T y)}{d(x, y)}, d(x, y)\right\} \\
& =k \max \left\{\frac{d(x, T x) \cdot d(y, T y)}{d(x, y)}, d(x, y)\right\}
\end{aligned}
$$

where $k=\alpha+\beta \in(0,1)$. Therefore, Corollary 2.2 is a generalization of Theorem 1.6, so is Theorem 2.1.

Now, we shall prove the uniqueness of the fixed point.

Theorem 2.4. In addition to the hypotheses of Theorem 2.1, suppose that

$$
\text { for every } x, y \in X \text {, there exists } z \in X \text { that is comparable to } x \text { and } y \text {, }
$$

then $T$ has a unique fixed point.

Proof. From Theorem 2.1, the set of fixed points of $T$ is non-empty. Suppose that $x, y$ $\in X$ are two fixed points of $T$. By the assumption, there exists $z \in X$ that is comparable to $x$ and $y$.

We define the sequence $\left\{z_{n}\right\}$ as follows

$$
z_{0}=z, z_{n+1}=T z_{n}, n=0,1,2, \ldots
$$

Since $z$ is comparable with $x$, we may assume that $z \leq x$. Using the mathematical induction, it is easy to show that $z_{n} \leq x$ for all $n$.

Suppose that there exists $n_{0} \geq 1$ such that $z_{n_{0}}=x$, then $z_{n}=T z_{n-1}=T x=x$ for all $n$ $\geq n_{0}-1$. Hence, $z_{n} \rightarrow x$ as $n \rightarrow \infty$. 
On the other hand, if $z_{n} \neq x$ for all $n$, from (4), we have

$$
\begin{aligned}
d\left(x, z_{n}\right)= & d\left(T x, T z_{n-1}\right) \\
\leq & \max \left\{\frac{d(x, T x) \cdot d\left(z_{n-1}, T z_{n-1}\right)}{d\left(x, z_{n-1}\right)}, d\left(x, z_{n-1}\right)\right\} \\
& -\varphi\left(\max \left\{\frac{d(x, T x) \cdot d\left(z_{n-1}, T z_{n-1}\right)}{d\left(x, z_{n-1}\right)}, d\left(x, z_{n-1}\right)\right\}\right) \\
= & d\left(x, z_{n-1}\right)-\varphi\left(d\left(x, z_{n-1}\right)\right.
\end{aligned}
$$

It implies that $d\left(x, z_{n}\right)<d\left(x, z_{n-1}\right)$ for all $n \geq 1$, that is, $\left\{d\left(x, z_{n}\right)\right\}$ is a decreasing sequence of positive real numbers. Therefore, there is an $\alpha \geq 0$ such that $d\left(x, z_{n}\right) \rightarrow \alpha$. We shall show that $\alpha=0$. Suppose, to the contrary, that $\alpha>0$. Taking the upper limit as $n \rightarrow \infty$ in (16) and using the properties of $\phi$, we have

$$
\alpha=\lim _{n \rightarrow \infty} d\left(x, z_{n}\right) \leq \alpha-\lim _{n \rightarrow \infty} \inf \varphi\left(d\left(x, z_{n-1}\right)\right) \leq \alpha-\varphi(\alpha)<\alpha
$$

which is a contradiction. Hence, $\alpha=0$, that is, $z_{n} \rightarrow x$ as $n \rightarrow \infty$. Therefore, in both cases, we have

$$
\lim _{n \rightarrow \infty} z_{n}=x
$$

Similarly, we have

$$
\lim _{n \rightarrow \infty} z_{n}=y
$$

From (17) and (18), we get $x=y$. $\square$

Example 2.5. Let $X=\left[0, \frac{1}{2}\right]$ with the usual metric $d(x, y)=|x-y|, \forall x, y \in X$. Obviously, $(X, d)$ is a complete metric space. We consider the ordered relation in $X$ as follows

$$
x, y \in X, x \preccurlyeq y \Leftrightarrow x=y \text { or }\left(x, y \in\{0\} \cup\left\{\frac{1}{n}: n=2,3, \ldots\right\} \text { and } x \leq y\right)
$$

where $\leq$ be the usual ordering.

Let $T: X \rightarrow X$ be given by

$$
T x=\left\{\begin{array}{cl}
0, & \text { if } x=0, \\
1 /(n+1), & \text { if } x=1 / n, n=2,3, \ldots \\
\sqrt{2} / 2, & \text { otherwise }
\end{array}\right.
$$

It is easy to see that $T$ is non-decreasing and $X$ has the property (2). Also, there is $x_{0}$ $=0$ in $X$ such that $x_{0}=0 \leqslant 0=T x_{0}$.

Clearly, $T$ has a fixed point that is 0 . However, we cannot apply Theorem 1.6 because the condition (3) is not true. Indeed, suppose that the condition (3) holds. Taking $y=0$ and $x=1 / n, n=2,3,4, \ldots$ in (3), we have

$$
d\left(T \frac{1}{n}, T 0\right) \leq \alpha \frac{d\left(\frac{1}{n}, T \frac{1}{n}\right) \cdot d(0, T 0)}{d\left(\frac{1}{n}, 0\right)}+\beta d\left(\frac{1}{n}, 0\right), \forall n=2,3,4, \ldots
$$

This implies

$$
\frac{1}{n+1} \leq \beta \frac{1}{n}, \quad \forall n=2,3,4, \ldots
$$


or

$$
\frac{n}{n+1} \leq \beta, \quad \forall n=2,3,4, \ldots
$$

Taking $n \rightarrow \infty$ in the last inequality, we have $1 \leq \beta$ and we obtain a contradiction.

We now show that $T$ satisfies (4) with $\phi:[0, \infty) \rightarrow[0, \infty)$ which is given by

$$
\varphi(t)=t^{3}, \forall t \in[0, \infty)
$$

We have $x, y \in X, x \geqslant y, x \neq y$ if $x=1 / n, y=0$ or $x=1 / n, y=1 / m, m>n \geq 2$. So, we have two possible cases.

Case 1. $x=1 / n, n \geq 2$ and $y=0$, we have

$$
M(x, y)-\varphi(M(x, y))=\frac{1}{n}-\frac{1}{n^{3}} \geq \frac{1}{n}-\frac{1}{n(n+1)}=\frac{1}{n+1}=d(T x, T y)
$$

Case 2. $x=1 / n, y=1 / m, m>n \geq 2$, we have

$$
M(x, y)=\max \left\{\frac{\left|\frac{1}{n}-\frac{1}{n+1}\right| \cdot\left|\frac{1}{m}-\frac{1}{m+1}\right|}{\left|\frac{1}{n}-\frac{1}{m}\right|},\left|\frac{1}{n}-\frac{1}{m}\right|\right\}
$$

For $m>n \geq 2$, we have

$$
\frac{\left|\frac{1}{n}-\frac{1}{n+1}\right| \cdot\left|\frac{1}{m}-\frac{1}{m+1}\right|}{\left|\frac{1}{n}-\frac{1}{m}\right|} \leq\left|\frac{1}{n}-\frac{1}{m}\right|
$$

is equivalent to

$$
\frac{1}{(n+1)(m+1)} \leq \frac{(m-n)^{2}}{m n}
$$

or

$$
\frac{m n}{(n+1)(m+1)} \leq(m-n)^{2}
$$

The last inequality holds since

$$
\frac{m n}{(n+1)(m+1)}<1 \leq(m-n)^{2}
$$

Therefore,

$$
M(x, y)=\left|\frac{1}{n}-\frac{1}{m}\right|
$$

We have

$$
d(T x, T y) \leq M(x, y)-\varphi(M(x, y)), \quad \forall m>n \geq 2
$$

is equivalent to

$$
\left|\frac{1}{n+1}-\frac{1}{m+1}\right| \leq\left|\frac{1}{n}-\frac{1}{m}\right|-\left|\frac{1}{n}-\frac{1}{m}\right|^{3}, \quad \forall m>n \geq 2
$$


or

$$
\frac{m-n}{(n+1)(m+1)} \leq \frac{m-n}{m n}-\frac{(m-n)^{3}}{(m n)^{3}}, \quad \forall m>n \geq 2
$$

or

$$
\frac{(m-n)^{2}}{(m n)^{3}} \leq \frac{1}{m n}-\frac{1}{(n+1)(m+1)}=\frac{m+n+1}{m n(n+1)(m+1)}, \quad \forall m>n \geq 2
$$

or

$$
\left(\frac{1}{n}-\frac{1}{m}\right)^{2} \leq \frac{m+n+1}{(n+1)(m+1)}, \quad \forall m>n \geq 2
$$

We have

$$
\left(\frac{1}{n}-\frac{1}{m}\right)^{2}<\frac{1}{n^{2}}<\frac{1}{n+1}+\frac{n}{(n+1)(m+1)}=\frac{m+n+1}{(n+1)(m+1)}, \quad \forall m>n \geq 2
$$

Thus, the inequality (20) holds, so does the inequality (19).

Therefore, all the conditions of Theorem 2.1 are satisfied. Applying Theorem 2.1, we conclude that $T$ has a fixed point in $X$.

Notice that since $T$ is not continuous, this example cannot apply to Theorem 1.1.

Moreover, since the condition (15) is not satisfied, the uniqueness of fixed point of $T$ does not guarantee. In fact, $T$ has two fixed points that are 0 and $\sqrt{2} / 2$.

\section{Acknowledgements}

The authors express their sincere thanks to the reviewers for their valuable suggestions in improving the paper.

\section{Authors' contributions}

All authors contribute equally and significantly in this research work. All authors read and approved the final manuscript.

\section{Competing interests}

The authors declare that they have no competing interests.

Received: 1 March 2011 Accepted: 5 September 2011 Published: 5 September 2011

\section{References}

1. Jaggi, DS: Some unique fixed point theorems. Indian J Pure Appl Math. 8, 223-230 (1977)

2. Ya, I, Alber, S: Guerre-Delabriere, Principles of weakly contractive maps in Hilbert spaces, new results in operator theory. In: Gohberg I, Lyubich Yu (eds.) Advances and Application, vol. 98, pp. 7-22. Birkhauser Verlag, Basel (1997)

3. Rhoades, BE: Some theorems on weakly contractive maps. Nonlinear Anal. 47, 2683-2693 (2001). doi:10.1016/50362546X(01)00388-1

4. Doric, D: Common fixed point for generalized $(\varphi$, $\psi$ )-weak contractions. Appl Math Lett. 22, 1896-1900 (2009). doi:10.1016/.aml.2009.08.001

5. Harjani, J, Sadarangani, K: Fixed point theorems for weakly contractive mappings in partially ordered sets. Nonlinear Anal. 71, 3403-3410 (2009). doi:10.1016/..na.2009.01.240

6. Harjani, J, Sadarangani, K: Generalized contractions in partially ordered metric spaces and applications to ordinary differential equations. Nonlinear Anal. 72, 1188-1197 (2010). doi:10.1016/j.na.2009.08.003

7. Radenovic, S, Kadelburg, Z: Generalized weak contractions in partially ordered metric spaces. Comput Math Appl. 60 , 1776-1783 (2010). doi:10.1016/j.camwa.2010.07.008

8. Popescu, O: Fixed points for $\varphi$-weak contractions. Appl Math Lett. 24, 1-4 (2011). doi:10.1016/j.aml.2010.06.024

9. Zhang, Q, Song, Y: Fixed point theory for generalized $\varphi$-weak contractions. Appl Math Lett. 22, 75-78 (2009). doi:10.1016/j.aml.2008.02.007

10. Ran, $A C M$, Reurings, $M C B$ : A fixed point theorem in partially ordered sets and some applications to matrix equations. Proc Am Math Soc. 132, 1435-1443 (2004). doi:10.1090/50002-9939-03-07220-4

11. Nieto, JJ, Rodrguez-Lopez, R: Contractive mapping theorems in partially ordered sets and applications to ordinary differential equations. Order. 22, 223-239 (2005). doi:10.1007/s11083-005-9018-5

12. Harjani, J, Lopez, B, Sadarangani, K: A fixed point theorem for mappings satisfying a contractive condition of rational type on a partially ordered metric space. Abstr Appl Anal. 2010, 1-8 (2010) 
13. Bhaskar, TG, Lakshmikantham, V: Fixed point theorems in partially ordered metric spaces and applications. Nonlinear Anal. 65, 1379-1393 (2006). doi:10.1016/j.na.2005.10.017

14. Agarwal, RP, El-Gebeily, MA, Regan, D: Generalized contractions in partially ordered metric spaces. Appl Anal. 87, 109-116 (2008). doi:10.1080/00036810701556151

15. Lakshmikantham, V, Ciric, L: Coupled fixed point theorems for nonlinear contractions in partially ordered metric spaces. Nonlinear Anal. 70, 4341-4349 (2009). doi:10.1016/j.na.2008.09.020

16. Luong, NV, Thuan, NX: Coupled fixed points in partially ordered metric spaces and application. Nonlinear Anal. 74 , 983-992 (2011). doi:10.1016/j.na.2010.09.055

17. Luong, NV, Thuan, NX: Coupled fixed point theorems in partially ordered metric spaces. Bull Math Anal Appl. 2(4), $16-24(2010)$

18. Nieto, JJ, Rodrguez-Lopez, R: Existence and uniqueness of fixed point in partially ordered sets and applications to ordinary differential equations. Acta Math Sin. 23, 2205-2212 (2007). doi:10.1007/s10114-005-0769-0

19. Regan, D, Petrusel, A: Fixed point theorems for generalized contractions in ordered metric spaces. J Math Anal Appl. 341(2), 1241-1252 (2008). doi:10.1016/j.jmaa.2007.11.026

doi:10.1186/1687-1812-2011-46

Cite this article as: Luong and Thuan: Fixed point theorem for generalized weak contractions satisfying rational expressions in ordered metric spaces. Fixed Point Theory and Applications 2011 2011:46.

\section{Submit your manuscript to a SpringerOpen ${ }^{\odot}$} journal and benefit from:

Convenient online submission

- Rigorous peer review

- Immediate publication on acceptance

- Open access: articles freely available online

- High visibility within the field

- Retaining the copyright to your article

Submit your next manuscript at $\boldsymbol{\wedge}$ springeropen.com 